\title{
Implementasi IoT Cerdas Berbasis Inference Fuzzy Tsukamoto Pada Pemantauan Kadar pH Dan Ketinggian Air Dalam Akuaponik
}

\author{
(Smart IoT Based Inference Fuzzy Tsukamoto Implementation on Monitoring pH \\ Levels and Water Height in Aquaponics)
}

\author{
Adlan Jiwa Kuswinta*, I Gede Putu Wirama Wedashwara W, I Wayan Agus Arimbawa \\ Dept Informatics Engineering, Mataram University \\ Jl. Majapahit 62, Mataram, Lombok NTB, INDONESIA \\ Email: adlan.kuswinta1996@gmail.com,wirarama@unram.ac.id, arimbawa@unram.ac.id
}

*Penulis korespondensi

\begin{abstract}
Increasing population and rapid development have resulted in reduced source of clean water, especially in urban areas. Fish and plant cultivation require good water quality so as not to be exposed to parasites and diseases that cause death. Aquaponic uses water continuously from the maintenance of fish which is then distributed to plants, and then returned to the fish pond. This aquaponics system will be implemented with IoT using microcontrollers, ultrasonic sensors, and pH sensors so that aquaponic owners do not need to manually check. This system is used to adjust the height and $\mathrm{pH}$ of water in aquaponics to remain stable by implementing the concept of IoT and Inference Fuzzy Tsukamoto. One method that can be used to control $\mathrm{pH}$ levels based on water height by adding or reducing water is to create a system that can inform good results using the fuzzy logic method and displayed through the website. The implementation of this system is focused on kangkung and mustard greens, and evaluations carried out are only pattern recognition rather than optimization. The aquaponics system that is made can run well and shows information based on the results of fuzzy calculations from the system with manual calculations. Based on the tests carried out, it was found that the $\mathrm{pH}$ meter sensor can measure water $\mathrm{pH}$ levels in aquaponics with an error tolerance of $6.3 \%$ from manual $\mathrm{pH}$ measuring devices, ultrasonic sensors can measure water levels in aquaponics with an error tolerance of $7.8 \%$ of measurements using a manual measuring meter, and an aquaponics system can display the conclusions of the calculation of fuzzy results according to the data on $\mathrm{pH}$ levels and water levels obtained from the sensor.
\end{abstract}

Key words: Internet of Things, Arduino Uno, pH meter, Ultrasonic, and Inference Fuzzy Tsukamoto.

\section{PENDAhuluan}

Jumlah Penduduk Kota Mataram sebesar 362.243 jiwa pada Desember 2008, dengan laju pertumbuhan rata-rata penduduk Kota Mataram sampai dengan tahun 2006 sebesar 2,82\% per tahun. Meningkatnya jumlah penduduk dan pesatnya pembangunan menyebabkan berkurangnya sumber air bersih, khususnya didaerah perkotaan [1].

Air bersih merupakan sumber utama yang sangat diperlukan makhluk hidup, khususnya dalam bidang perikanan dan pertanian. Budidaya ikan dan tanaman memerlukan kualitas air yang baik, agar tidak terkena parasit dan penyakit yang mengakibatkan kematian [2]. Air berkualitas baik tidak hanya didapatkan dari air baru, tetapi bisa didapatkan dengan menggunakan kembali air yang telah terpakai, seperti pada sistem akuaponik.

Sistem akuaponik merupakan metode pertanian perpaduan antara akuakultur dengan hidroponik. Akuakultur adalah budidaya ikan, sedangkan hidroponik adalah budidaya tanaman yang memanfaatkan air sebagai kebutuhan media tanam. Akuaponik memanfaatkan air secara terus menerus dari hasil pemeliharaan ikan yang kemudian disalurkan ke tanaman, dan selanjutnya dikembalikan lagi ke kolam ikan [3]. Sistem akuaponik terdapat kadar $\mathrm{pH}$ dan ketinggian air yang sangat penting dalam pertumbuhan ikan dan tanaman agar kesehatannya dapat terjaga dengan baik, sehingga kadar $\mathrm{pH}$ air dan ketinggian air harus stabil. Hal tersebut dapat dilakukan dengan pemantauan kestabilan kadar $\mathrm{pH}$ air dan ketinggian air dengan penggunaan Internet of Thing (IoT). Pengambilan data secara berskala sangat dibutuhkan untuk mendapatkan informasi kondisi kadar $\mathrm{pH}$ dan ketinggian air dalam akuaponik. Melakukan pengecekan kadar ph dan ketinggian air membutuhkan teknologi yang dapat mengambil data secara digital yaitu dengan menggunakan sensor-sensor yang terdapat pada IoT.

Internet of Things (IoT) merupakan kumpulan bendabenda (things), berupa perangkat fisik (hardware/embedded sistem) yang mampu bertukar informasi antar sumber informasi, operator layanan ataupun perangkat lainnya yang terhubung kedalam sistem sehingga dapat memberikan kemanfaatan yang lebih besar [4]. Sistem akuaponik ini akan diimplementasikan dengan IoT menggunakan microcontroller, sensor ultrasonik dan sensor $\mathrm{pH}$ yang akan memberikan informasi melalui website. Informasi-informasi yang akan diberikan berupa kestabilan kadar $\mathrm{pH}$ air dan ketinggian air pada kolam ikan. Pengecekan kestabilan kadar $\mathrm{pH}$ air dan ketinggian air ini dimaksudkan untuk menjaga tanaman agar dapat menyerap 
nutrisi secara maksimal dari air. Salah satu cara yang dapat digunakan untuk menjaga kadar $\mathrm{pH}$ berdasarkan ketinggian air dengan cara menambah atau mengurangi air adalah dengan membuat sebuah sistem yang dapat menginformasikan hasil yang bagus dengan menggunakan metode logika fuzzy.

Logika fuzzy digunakan karena metode tersebut terkenal dapat mengakomodir data bukan biner dan bersifat non linier sehingga logika fuzzy cocok digunakan karena menggunakan nilai linguistic yang tidak linier. Logika fuzzy digunakan karena adanya batas-batas nilai sensor, maka akan dibuat parameter untuk menambahkan air atau mengganti air berdasarkan keadaan kadar $\mathrm{pH}$ dan ketinggian air. Sistem fuzzy tsukamoto memungkinkan untuk menyimpulkan hasil implikasi menjadi lebih sederhana, kemudian perhitungan defuzzifikasi menjadi lebih mudah, yang langsung menentukan arahan atau keluaran tegas sesuai dengan masukan yang diterima. Sehingga kesimpulan perolehan identifikasi air akan lebih akurat berdasarkan nilai kontradiksi. [5]

Rancang bangun mencakup pembangunan komponen elektronika dan sistem informasi berbasis web dengan integrasi Inference Fuzzy Tsukamoto. Melihat potensi tersebut maka diusulkan implementasi IoT pada akuaponik dengan melibatkan microcontroller, sensor $\mathrm{pH}$ meter dan sensor ultrasonik.

\section{TINJAUAN PUSTAKA}

Penelitian terkait sistem pengontrolan $\mathrm{pH}$ air dan ketinggian air pernah dilakukan, karena dapat membantu untuk menjaga kestabilan kadar $\mathrm{pH}$ pada air dan menjaga ketinggian air pada kolam ikan.

Penelitian yang membahas tentang pemanfaatan sistem mikrokontroller yang dihubungkan pada sensor suhu, $\mathrm{pH}$ Meter, sensor Water Level untuk pemantauan dan kontrol kondisi air dan pemberian pakan sesuai dengan kebutuhan usia perkembangan ikan lele yang dapat dilakukan secara otomatis, air dapat dikuras dan dipasok secara otomatis dipantau melalui layanan Ubidots IoT Cloud yang dikirim melalui Ethernet Shield, notifikasi ke email dan sms berhasil diterima pengguna ketika terpenuhi Event Trigger Ubidots [6].

Penelitian selanjutnya yang membahas tentang sistem kontrol yang mengimplementasikan metode fuzzy untuk mengolah data derajat keasaman dan ketinggian air akuarium, kemudian diproses didalam mikrokontroller Arduino Uno. Pada pengujian metode fuzzy Mamdani pengolahan fuzzy dari sistem dan secara manual pengujian dilakukan dengan menganalisis bahwa rumus fuzzy yang diterapkan pada sistem dapat menghasilkan output yang sesuai dengan perhitungan fuzzy. [2].

Penelitian selanjutnya yang membahas tentang memonitoring secara berkala untuk menjaga kestabilan kadar $\mathrm{pH}$ dan suhu air. Untuk menjaga kestabilan kadar $\mathrm{pH}$ dapat dilakukan dengan penggantian air baru jika nilai $\mathrm{pH}$ diluar batas normal. Penelitian ini membuat otomatisasi monitoring kadar $\mathrm{pH}$ dan suhu dengan menggunakan Electrode Eutech Instrument $\mathrm{pH}$ Meter Kit sebagai sensor
$\mathrm{pH}$, LM35 sebagai sensor suhu serta pengontrolan ketinggan air menggunakan sensor ultrasound HCSR-04. Output pengukuran $\mathrm{pH}$ dan suhu air ditampilkan pada layar LCD dan pada monitor dalam bentuk grafik sehingga memudahkan pembudidaya ikan lele memonitoring kondisi air kolam ikan [7].

Penelitian selanjutnya yang membahas tentang membuat suatu sistem pensimulasian lampu lalu lintas dan Autotuning Kendali PD dengan metode Tsukamoto menggunakan Mikrokontroler ATMEGA 16. [8] [9]

Berdasarkan pemaparan tinjauan pustaka di atas maka dalam tugas akhir ini akan dilakukan sebuah percobaan untuk membuat sebuah sistem pemantauan $\mathrm{pH}$ air dan ketinggian air dalam akuaponik dengan platform IoT yang menggunakan Arduino Uno sebagai pusat kontrol. Sistem ini dibangun untuk memantau keadaan $\mathrm{pH}$ air dan ketinggian air dengan sistem informasi berbasis web dengan integrasi Inference Fuzzy Tsukamoto.

\section{Metode Penelitian}

\section{A. Alat dan Bahan}

Berikut adalah alat dan bahan yang digunakan pada penelitian ini.

- Laptop Core 17 dengan RAM 4GB.

- Rangkaian Akuaponik (Kolam ikan, pot tanaman, pompa air, dan pipa air.

- Arduino Uno.

- Ethernet shield.

- Sensor pH meter.

- Sensor ultrasonik.

- Arduino IDE.

- Sublime text.

- XAMPP.

- CodeIgniter.

\section{B. Perancangan Arsitektur Sistem}

Pada tahap perancangan arsitektur sistem akan dilakukan perancangan terhadap arsitektur dan alur kerja dari sistem pemantauan akuaponik yang akan dibangun.

\section{B.1. Arsitektur sistem}

Gambaran dari arsitektur sistem informasi akuaponik dengan menggunakan Arduino Uno yang akan dibangun dapat dilihat pada Gambar 1.

Gambaran arsitektur sistem pemantauan akuaponik yang dimana pengukuran ini menggunakan sensor $\mathrm{pH}$ meter dan sensor ultrasonik yang merupakan sensor kadar $\mathrm{pH}$ air dan ketinggian air. Adapun penjelasan dari arsitektur sistem adalah sebagai berikut:

- Proses yang terjadi pada proses nomor 1 adalah sensor pH meter menerima masukan berupa kadar $\mathrm{pH}$, sensor ultrasonik menerima masukkan berupa ketinggian air dan setelah itu sensor $\mathrm{pH}$ meter dan sensor ultrasonik akan mengirimkan masukan yang telah didapatkan ke Arduino Uno. 
- Proses yang terjadi pada proses nomor 2 adalah Arduino Uno mengirim data kadar $\mathrm{pH}$ dan ketinggian air yang diterima oleh sensor ke database.

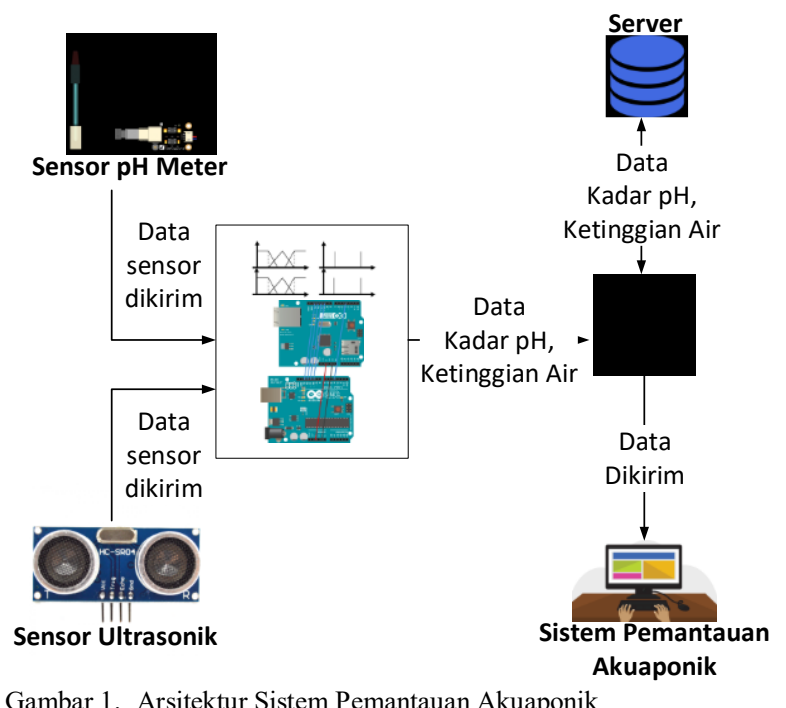

- Proses yang terjadi pada proses nomor 3 data kadar $\mathrm{pH}$ dan ketinggian air tersimpan dalam database.

- Proses yang terjadi pada proses nomor 4 adalah pengiriman pemberitahuan melalui internet ke sistem informasi akuaponik sehingga pemilik tanaman akuaponik dapat mengetahui keadaan $\mathrm{pH}$ dan ketinggian air.

\section{B.2. Fuzzy Inference Sistem}

Secara umum dengan menggunakan metode fuzzy Tsukamoto terdapat empat langkah dalam menentukan pemantauan akuaponik, berikut diagram alir untuk sistematika penentuan pemantauan dengan metode fuzzy Tsukamoto:

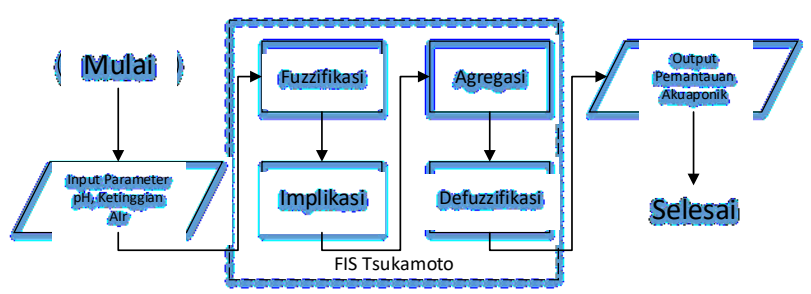

Gambar 2. Alur kerja sistem saat mendeteksi kebakaran

Untuk mendapatkan keluaran diperlukan empat tahapan:

1) Fuzzifikasi

Pada metode Tsukamoto, baik variabel input maupun variabel output dibagi menjadi satu atau lebih himpunan Fuzzy. Berikut merupakan gambaran kurva fungsi keanggotaan yang akan digunakan pada penelitian ini :

\section{a) Fungsi keangotaan variabel kadar $\mathrm{pH}$}

Pada variabel kadar $\mathrm{pH}$, terdapat beberapa himpunan keanggotaan untuk mencari nilai keanggotaan, sebagai contoh yaitu terdapat tiga himpunan keanggotaan yaitu
pH_Rendah, $\mathrm{pH}$ _Normal, dan $\mathrm{pH}$ _Tinggi seperti pada Gambar 3

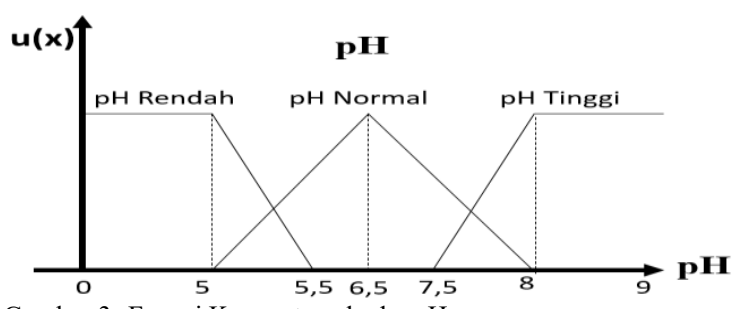

Gambar 3. Fungsi Keangotaan kadar $\mathrm{pH}$

Fungsi derajat keanggotaan yang digunakan sebagai contoh yaitu menghasilkan luaran berupa tingkat kadar $\mathrm{pH}$ dalam satuan $\mathrm{pH}$. Nilai kadar $\mathrm{pH}$ rendah $(5 \mathrm{pH})$, nilai kadar $\mathrm{pH}$ normal $(6,5 \mathrm{pH})$, dan nilai kadar $\mathrm{pH}$ tinggi $(8 \mathrm{pH})$. Gambar 3 hanya menunjukkan contoh skala jumlah $\mathrm{pH}$ pada penerapan fungsi deffuzification akan menyesuaikan berdasarkan pengenalan pola. Hal tersebut berarti menunjukkan bahwa sistem yang akan dibangun bisa beradaptasi di segala jenis dan jumlah ikan dan ukuran kolam ikan pada akuaponik.

b) Fungsi keangotaan variabel Ketinggian Air

Pada variabel Ketinggian Air, terdapat beberapa himpunan keanggotaan untuk mencari nilai keanggotaan, sebagai contoh yaitu terdapat tiga himpunan keanggotaan yaitu Air_Rendah, Air_Normal, dan Air_Tinggi seperti pada Gambar 4

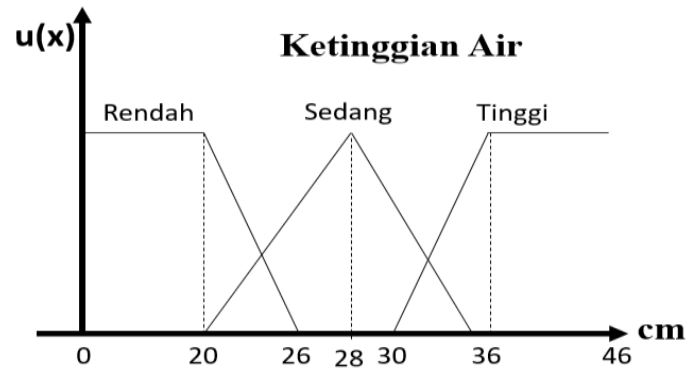

Gambar 4. Fungsi Keangotaan Ketinggian Air

Fungsi derajat keanggotaan yang digunakan sebagai contoh yaitu menghasilkan luaran berupa jumlah air berdaasarkan ketinggian kolam dalam satuan centimeter $(\mathrm{cm})$. Nilai ketingian air rendah $(20 \mathrm{~cm})$, nilai ketinggian air sedang $(28 \mathrm{~cm})$, dan nilai ketinggian air tinggi $(36 \mathrm{~cm})$. Gambar 4 hanya menunjukkan contoh skala jumlah air, pada penerapan fungsi defuzzifikasi akan menyesuaikan berdasarkan pengenalan pola. Hal tersebut berarti menunjukkan bahwa sistem yang akan dibangun bisa beradaptasi di segala ukuran kolam ikan pada akuaponik.

c) Fungsi keangotaan variabel kesimpulan Kontrol Air

Pada variabel kesimpulan Kontrol Air, terdapat beberapa himpunan keanggotaan untuk mencari nilai keanggotaan, sebagai contoh yaitu terdapat tiga himpunan keanggotaan yaitu Tambah Rendah, Tambah Sedang, dan Ganti Air seperti pada Gambar 5. 


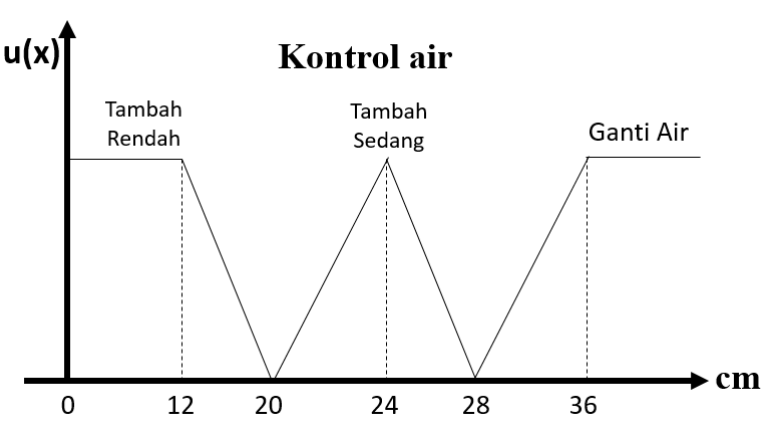

Gambar 5. Fungsi Keangotaan kesimpulan kontrol air

Fungsi deffuzification yang digunakan sebagai contoh yaitu menghasilkan luaran berupa jumlah air berdasarkan ketinggian kolam dalam satuan sentimeter $(\mathrm{cm})$. Nilai kontrol air tambah rendah $(20 \mathrm{~cm})$, nilai kontrol air tambah sedang $(28 \mathrm{~cm})$, dan nilai kontrol air ganti air $(36 \mathrm{~cm})$. Gambar 5 hanya menunjukkan contoh skala jumlah air berdasarkan ketinggian kolam pada penerapan fungsi deffuzification akan menyesuaikan berdasarkan pengenalan pola. Hal tersebut berarti menunjukkan bahwa sistem yang akan dibangun bisa beradaptasi di segala ukuran kolam ikan pada akuaponik.

2) Aplikasi fungsi implikasi

Implikasi adalah proses penarikan kesimpulan dari IFTHEN rule, dalam metode Tsukamoto penarikan kesimpulan menggunakan fungsi implikasi MIN.

Aturan/rule pada sistem fuzzy dibuat terlebih dahulu dari beberapa kombinasi himpunan fungsi keanggotaan yang ada, pada contoh himpunan keanggotaan variabel kadar $\mathrm{pH}$ terdapat tiga himpunan keanggotaan, variabel ketinggian air terdapat tiga himpunan keanggotaan. Jadi jika dikombinasikan terdapat 3 × $3=9$ kombinasi aturan dari 2 variabel di atas. Alur aturan Inference Fuzzy Tsukamoto dapat dilihat pada tabel I.

TABEL I. TABEL I. ATURAN FUZZY

\begin{tabular}{|c|c|c|c|}
\hline K_Ain & Rendah & Normal & Tinggi \\
\hline Rendah & $\begin{array}{c}\text { Tambah } \\
\text { Sedang }\end{array}$ & $\begin{array}{c}\text { Tambah } \\
\text { Sedang }\end{array}$ & $\begin{array}{c}\text { Tambah } \\
\text { Sedang }\end{array}$ \\
\hline Sedang & $\begin{array}{c}\text { Tambah } \\
\text { Sedikit }\end{array}$ & $\begin{array}{c}\text { Tambah } \\
\text { Sedikit }\end{array}$ & $\begin{array}{c}\text { Tambah } \\
\text { Sedikit }\end{array}$ \\
\hline Tinggi & $\begin{array}{c}\text { Ganti } \\
\text { Air }\end{array}$ & - & $\begin{array}{c}\text { Ganti } \\
\text { Air }\end{array}$ \\
\hline
\end{tabular}

\section{3) Agregasi}

Pada tahap selanjutnya, sistem akan melakukan proses agregasi untuk menentukan sebuah kombinasi rule dari beberapa rule yang terbentuk.

\section{4) Penegasan (defuzzifukasi)}

Metode defuzzyfikasi ini adalah metode yang digunakan pada metode Tsukamoto, dimana solusi crisp diperoleh dengan cara mengambil nilai rata-rata secara terpusat yang dapat dilakukan dengan rumus berikut.

$$
z^{*}=\frac{\sum_{i=1}^{N} a_{i} z_{i}}{\sum_{i=1}^{N} a_{i}}
$$

\section{Rancangan Perangkat Keras}

Perancangan perangkat keras sistem dapat dilihat pada gambar 6. Dimana controller yang digunakan disini adalah Arduino Uno. Untuk pemrosesan data yang didapat oleh sensor digunakan Arduino Uno. Untuk memproses data sensor lebih lanjut maka digunakan sistem pemantauan akuaponik yang berbasis fuzzy inference sistem untuk mendapatkan pemantauan kadar $\mathrm{pH}$ dan ketinggian air.

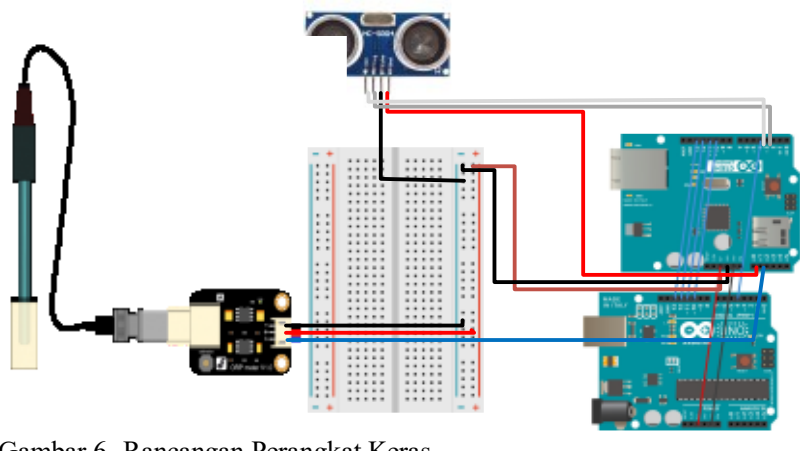

Gambar 6. Rancangan Perangkat Keras

\section{Rancangan Database}

Pada perancangan sistem pemantauan akuaponik berbasis IoT ini memiliki 3 entitas yaitu entitas seperti pada gambar 7.
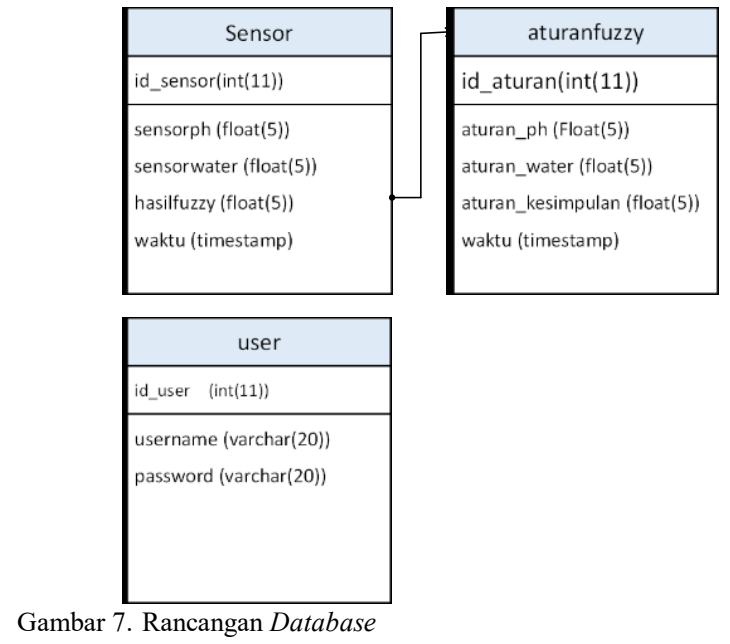

Masing-masing entitas memiliki fungsi sebagai berikut.

1) Tabel sensor

Tabel sensor digunakan untuk menyimpan data dari sensor $\mathrm{pH}$ meter, sensor kadar air, dan hasil dari fuzzy, dimana sensor tersebut dipasang pada rangkaian sistem akuaponik.

\section{2) Tabel aturanfuzzy}

Tabel aturanfuzzy digunakan untuk menyimpan data dari aturan fuzzy yang telah ditetapkan untuk mendapatkan kesimpulan dari hasil fuzzy.

\section{3) Tabel user}

Tabel user digunakan untuk menyimpan username dan password dari akun sistem informasi akuaponik. 


\section{E. Rancangan Perangkat Lunak}

Pada sistem pemantauan akuaponik dengan menggunakan Arduino Uno yang akan dibangun terdapat 2 buah aplikasi yang dibuat, yaitu Control Application dan Sistem Pemantauan Akuaponik. Rancangan dari masingmasing sub-sistem tersebut yaitu:

\section{E.1. Rancangan control application}

Control Application merupakan aplikasi yang akan dipasangkan pada Arduino Uno dan digunakan untuk mengendalikan sensor dan modul untuk dapat menerima input dan memberikan output. Control Application akan dibangun menggunakan bahasa pemrograman $\mathrm{C}$. Rancangan dari Control Application dapat dilihat pada gambar berikut ini:

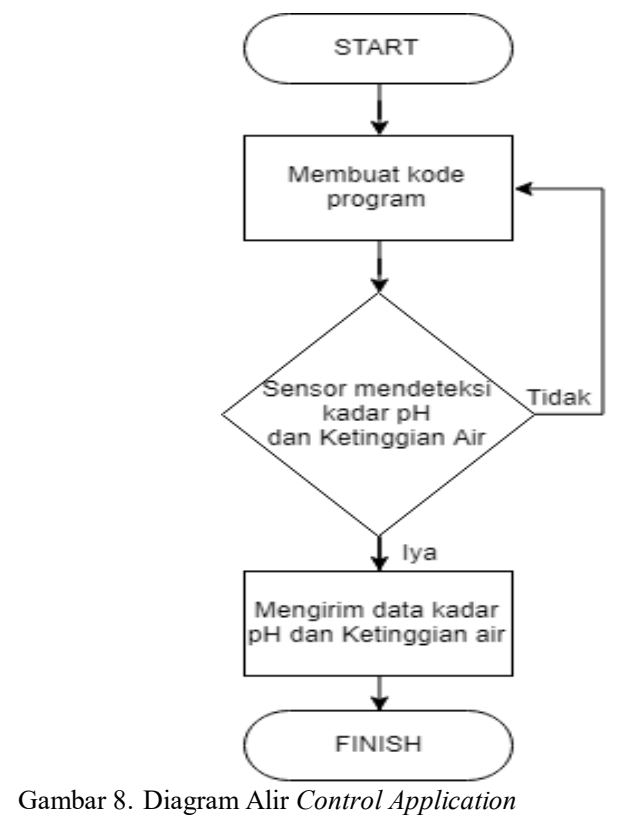

\section{E.2. Rancangan sistem informasi}

Sistem pemantauan akuaponik merupakan aplikasi berbasis web untuk melihat data kadar $\mathrm{pH}$ dan ketinggian air yang dimana nantinya data tersebut akan di olah untuk menentukan pemantauan ketinggian air. Pengembangan aplikasi web ini berbasis pada framework Codeigniter dengan rancangan usecase dan user interface sebagai berikut.

\section{E.3. Use case diagram}

Gambaran usecase aplikasi pemantauan akuaponik dapat dilihat pada gambar 9. dimana pengguna dapat melakukan login, setelah melakukan login, dapat melihat data kadar $\mathrm{pH}$ dan ketinggian air serta kesimpulan yang akan dilakukan tambah air atau ganti air dan terakhir user dapat melakukan logout dari sistem.

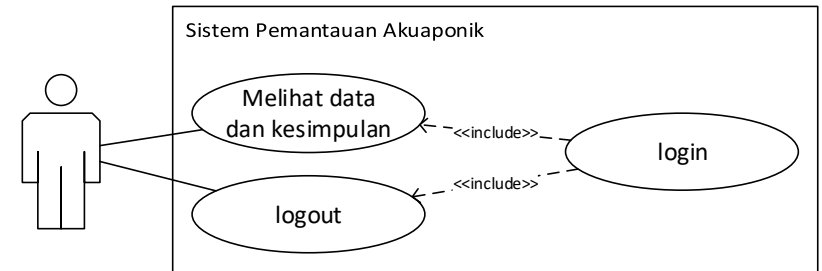

Gambar 9. Use Case Diagram Sitem Informasi Akuaponik

\section{F. Implementasi Sistem}

Setelah tahap perancangan akan dilakukan proses implementasi. Terdapat empat tahap dalam implementasi yaitu penyusunan perangkat, pembangunan Control Application, pembangunan Sistem Pemantauan Akuaponik, dan pembangunan database.

\section{F.1. Penyusunan perangkat}

Pada tahap penyusunan perangkat Arduino Uno, sensor $\mathrm{pH}$ meter dan ultrasonik akan dihubungkan menggunakan kabel jumper. Proses penyusunan perangkat akan dilakukan sesuai dengan rancangan perangkat keras pada tahap perancangan perangkat keras.

\section{F.2. Pembangunan control application}

Pada tahap pembangunan Control Application, rancangan Control Application akan diimplementasikan ke dalam Arduino Uno dengan menggunakan bahasa pemrograman $\mathrm{C}++$. Arduino IDE akan digunakan sebagai alat bantu dalam proses implementasi Control Application ke dalam Arduino Uno.

\section{F.3. Pembangunan database}

Pada tahap pembangunan Database, rancangan Database akan diimplementasikan dalam Arduino Uno dengan menggunakan MySql. XAMPP akan digunakan sebagai alat bantu dalam proses implementasi Database ke dalam Arduino Uno.

\section{F.4. Pembangunan Sistem Pemantauan Akuaponik}

Pada tahap pembangunan sistem pemantauan akuaponik, rancangan dari Sistem pemantauan akuaponik akan dibuat dalam bentuk Web Service yang akan diimplementasikan ke dalam Arduino Uno dengan menggunakan framework Codeigniter. Sublime Text digunakan sebagai alat bantu dalam proses implementasi Web Service ke dalam Arduino Uno dan pembangunan Sistem Informasi Akuaponik.

\section{G. Pengujian Sistem}

Pada tahap pengujian dan evaluasi sistem, akan dilakukan pengujian terhadap sistem yang telah dibangun. Pada penelitian ini, teknik pengujian dengan menggunakan metode black box sebagai metode pengujian fungsionalitas software sistem dalam memonitoring. Metode pengujian black box digunakan untuk mengetahui apakah sistem dapat memonitoring sistem pemantauan akuaponik dikarenakan metode pengujian black box ini berfungsi untuk mengetahui kinerja yang ada pada sistem informasi akuaponik dapat berfungsi dengan baik dan benar. [10] 
Pada tahap ini akan dilakukan pengujian terhadap sistem yang dilakukan pada ember kolam ikan akuaponik sebagai sampel pengujian. Adapun tahapan pengujiannya adalah sebagai berikut.

\section{G.1. Pengujian perangkat keras}

Pada pengujian perangkat keras, akan diuji apakah masing-masing sensor dapat melakukan identifikasi berdasarkan data input yang dapat diterima seperti sensor pH meter dan ultrasonik. Apabila sensor $\mathrm{pH}$ meter dan ultrasonik belum dapat membaca data input maka akan dilakukan perangkaian ulang agar dapat menerima input berupa data kadar $\mathrm{pH}$ dan ketinggian air. Dilakukan juga pengujian sensor $\mathrm{pH}$ meter dengan alat ukur $\mathrm{pH}$ meter manual sebagai validasi kesesuaian data yang diterima. Begitu juga dengan perangkat Arduino Uno akan dilakukan ujicoba apakah dapat mengirimkan data sensor ke dalam database yang ada pada Arduino Uno sebagai bahan untuk pemantauan akuaponik nantinya.

\section{G.2. Pengujian sistem pemantauan Akuaponik}

Pada pengujian sistem pemantauan akuaponik akan diuji apakah dapat digunakan untuk menerima data dari modul dan sensor agar dapat mengetahui keadaan kadar $\mathrm{pH}$ dan ketinggian air. Kemudian akan diuji juga apakah sistem dapat menampilkan data berdasarkan data yang dikirimkan perangkat sensor dan modul melalui perangkat Arduino Uno.

\section{G.3. Pengujian Dengan Logika Fuzzy Tsukamoto}

Hasil dari data kadar $\mathrm{pH}$ dan ketinggian air tersebut akan menghasilkan informasi akuaponik berupa pemantauan air. Informasi ini merupakan hasil yang ditentukan oleh sistem itu sendiri berdasarkan dengan Inference Fuzzy Tsukamoto, disini user hanya mengimplementasikan aturan yang sudah ada kedalam program dan selanjutnya sistem yang akan menentukan hasilnya. Kemudian hasil pengujian dari sistem dibandingkan dengan perhitungan secara manual.

\section{HASil Dan PEMBAHASAN}

\section{A. Realisasi Sistem}

Pada bab ini, akan membahas hasil dari penelitian yang dilakukan yaitu "Implementasi IOT Cerdas Berbasis Inference Fuzzy Tsukamoto Berdasarkan Kadar pH dan Ketinggian air Pada Tanaman Dalam Akuaponik". Realisasi yang dilakukan telah dibuat sesuai dengan perancangan yang dijabarkan pada bab sebelumnya. Pembahasan yang akan dijelaskan meliputi Realisasi penyusunan perangkat keras, Realisasi pembangunan Control Application, Realisasi pembangunan Web Service, dan Realisasi pembangunan Database. Selain itu, pada bab ini juga akan dibahas mengenai hasil sistem yang telah dibuat berdasarkan perancangan yang ada, melakukan pengujian sistem serta mengevaluasi sistem yang telah berjalan.

\section{A.1. Realisasi penyusunan perangkat keras}

Realisasi penyusunan perangkat keras dari Implementasi IOT Cerdas Berbasis Inference Fuzzy Tsukamoto pada Tanaman Dalam Akuaponik dapat dilihat pada Gambar 10 yang mengacu kepada rancangan perangkat keras pada Gambar 6.

a

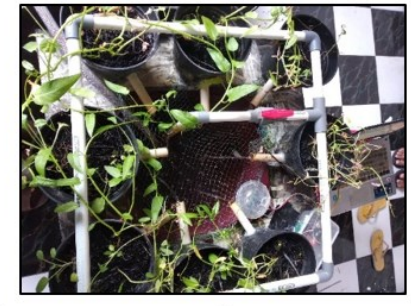

b
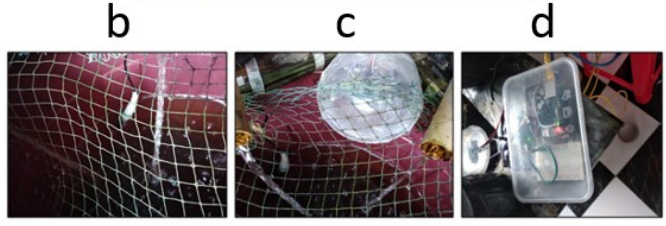

Gambar 10. Realisasi Penyusunan Perangkat Keras Implementasi Sistem Akuaponik

Pada tahap realisasi perangkat keras ini, perangkat dirangkai berdasarkan rancangan yang telah dibuat pada bab sebelumnya. Pada gambar 10 terdapat empat perangkat keras yang dihubungkan menjadi sebuah perangkat sistem akuaponik yang terdiri dari Arduino Uno, sensor pH meter, senseor ultrasonik, dan Ethernet Shield. Fungsi dari alat-alat tersebut adalah:

- Gambar 10 a merupakan Ukuran diameter kolam ikan pada akuaponik yaitu $35 \mathrm{~cm}$ x $35 \mathrm{~cm}$.

- Gambar 10 d Arduino Uno digunakan sebagai mikrokontroler dari sistem akuaponik.

- Gambar 10 b Sensor pH meter digunakan untuk mengukur kadar $\mathrm{pH}$ yang terdapat pada air kolam.

- Gambar 10 c Sensor ultrasonik digunakan untuk menggetahui ketinggian dari air kolam.

- Gambar 10 d Ethernet Shield digunakan sebagai penghubung Arduino Uno ke internet agar dapat mengakses web service.

\section{A.2. Realisasi pembangunan control application}

Dalam realisasi pembangunan control application bahasa yang digunakan bahasa c, dan IDE yang digunakan adalah Arduino IDE. Untuk membangun control application agar semua sensor dan modul dapat terkoneksi satu sama lain dan sistem dapat berjalan sesuai dengan yang diinginkan, maka dibuatlah source code yang memiliki alur seperti yang ditunjukkan pada Gambar 11 berikut. 


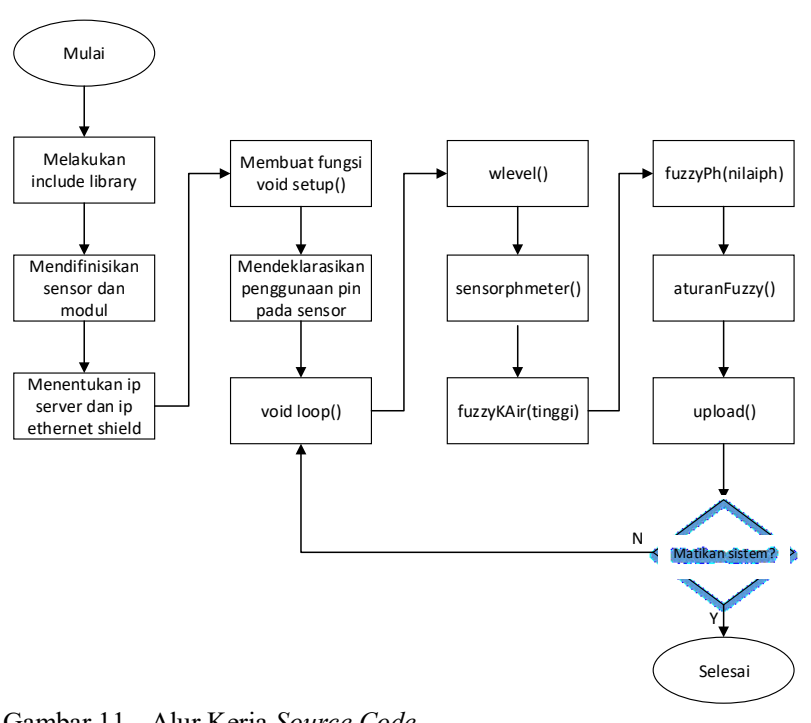

Gambar 11. Alur Kerja Source Code

Berdasarkan Gambar 11 alur kerja yang dilakukan dapat dijelaskan bahwa pertama yang dilakukan yaitu include library berdasarkan modul yang digunakan. Kemudian yang kedua yaitu mendefinisikan pin yang digunakan sensor dan modul. Selanjutnya yaitu menentukan IP Address dari server dan Ethernet shield. IP Address server berguna sebagai alamat untuk mengirimkan data dari Arduino, sedangkan IP Address Ethernet shield berguna sebagai alamat agar Arduino bisa mendapatkan akses internet. Kemudian setelah itu membuat fungsi inti dari sistem, yaitu method void setup() dan method void loop(). Pada method void setup(), dilakukan pendeklarasian kegunaan pin pada sensor yakni sebagai pin output, pada method void loop(), yang pertamakali dilakukan adalah menjalankan method wlevel() yang berfungsi untuk menjalankan sensor ultrasonik sebagai nilai dari ketinggian pada air kolam. Kemudian menjalan kan method sensorphmeter() yang berfungsi untuk menjalankan sensor pH meter sebagai nilai dari kadar $\mathrm{pH}$ pada air kolam. Setelah mendapatkan nilai derajat keanggotaan dari parameter ketinggian air dan kadar $\mathrm{pH}$, selanjutnya menjalankan method aturanfuzzy() yang berfungsi sebagai tahap defuzzyfikasi untuk menentukan aturan yang telah dibuat berdasarkan nilai derajat keanggotaan yang telah didapatkan sebagai penentuan dari kesimpulan fuzzy yang telah ditetapkan. Method upload() berfungsi untuk mengirimkan data ketinggian air dan kadar $\mathrm{pH}$ ke dalam database. Jika sistem dalam keadaan menyala maka akan tetap menjalankan method void loop(), apabila sistem dimatikan maka proses akan selesai.

\section{A.3. Realisasi pembangunan web service}

Dalam realisasi pembuatan web service bahasa yang digunakan adalah bahasa PHP dan dengan menggunakan framework CodeIgniter. Struktur folder yang terdapat pada CodeIgniter dapat dilihat pada Gambar 12.

\begin{tabular}{|c|c|}
\hline FOLDERS & $\checkmark \square$ third_party \\
\hline$\nabla \mathscr{b}$ akuaponik & $\nabla \curvearrowleft$ views \\
\hline$\nabla \curvearrowleft$ application & $\square$ errors \\
\hline$\checkmark$ cache & footer.php \\
\hline$\checkmark$ config & Tead.php \\
\hline$\nabla \square$ controllers & home.php \\
\hline 圆 Home.php & index.html \\
\hline 圆 Welcome.php & login.php \\
\hline$\checkmark$ core & 0 .htaccess \\
\hline$\checkmark \checkmark$ helpers & index.html \\
\hline$\checkmark \square$ hooks & $\checkmark$ assets \\
\hline$\triangleright \square$ language & $\checkmark \square$ libraries \\
\hline$\checkmark$ libraries & $\checkmark \checkmark$ startbootstrap-sb-admin-gh-pag \\
\hline$>\square \log s$ & $\checkmark$ system \\
\hline$\nabla \sigma$ models & $\square$ tests \\
\hline 国 index.html & $\checkmark \square$ user_guide \\
\hline Godelwelcome.php & $\square$ vendor \\
\hline
\end{tabular}

Gambar 12. Struktur folder web service file controller, file model dan file view pada CodeIgniter

Selain dengan menggunakan framework CodeIgniter, terdapat juga beberapa file code dengan menggunakan bahasa PHP yang berfungsi untuk membantu hardware dalam mengirimkan data ke database. File code PHP tersebut dapat dilihat pada Gambar 13.

FOLDERS
$\begin{aligned} & \text { skripsi } \\ & \text { akuaponik_fuzzy.php } \\ & \text { aturanfuzzy.php } \\ & \text { connection.php } \\ & \text { fuzifikasiph.php } \\ & \text { fuzzifikasiwater.php }\end{aligned}$

Gambar 13. File code PHP untuk hardware mengirim data ke database

\section{A.4. Realisasi pembangunan sistem pemantauan Akuaponik}

Dalam pembuatan sistem pemantauan akuaponik digunakan bahasa PHP dan dengan framework CodeIgniter. Pada sistem pemantauan akuaponik tersebut terdapat beberapa halaman yang dibuat yakni halaman login, dashboard, dan statistik. Pada halaman login sistem pemantauan akuaponik, peneliti diharuskan untuk mengisikan email address dan password agar bisa mengakses sistem pemantauan akuaponik. Setelah login berhasil, sistem akan menampilkan halaman dashboard yang akan menampilkan tabel data keadaan kadar $\mathrm{pH}$ dan ketinggian air serta kesimpulan hasil fuzzy. Pada halaman statistik untuk menampilkan data statistik kesimpulan fuzzy. Berikut adalah contoh tampilan untuk halaman dashboard.

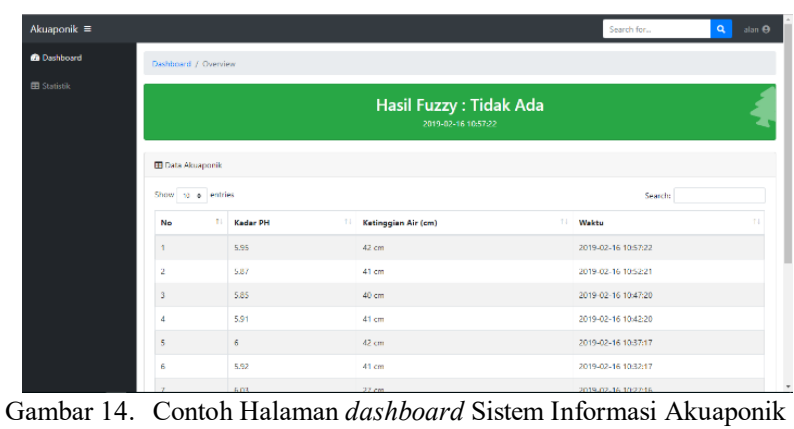




\section{B. Pengujian Sistem}

Pengujian implementasi sistem akuaponik ini dilakukan dengan cara metode pengujian black box yaitu menguji perangkat dari segi spesifikasi fungsional tanpa menguji desain dan kode program. Maksud dari pengujian ini yaitu dapat mengetahui apakah fungsi-fungsi dan keluaran sudah berjalan sesuai dengan harapan atau tidak. Berikut merupakan hasil pengujian yang telah dilakukan pada implementasi sistem akuaponik.

\section{B.1. Hasil Pengujian Sensor pH Meter}

Pengujian sensor $\mathrm{pH}$ meter ini, sensor ini ditempatkan pada bagian dalam akuaponik yang telah dibuat. Melakukan pengujian terhadap sensor agar dapat membaca kadar $\mathrm{pH}$ air. Pengujian dilakukan dengan menggunakan tiga jenis larutan yang berbeda yaitu larutan asam (borax), air normal, dan larutan basa (air sabun). . Hasil yang didapat memiliki toleransi error sebesar 6,3\% dari alat ukur pH manual sebagai nilai sebenarnya. Berdasarkan pengujian yang dilakukan, maka didapatkan hasil seperti pada Tabel II.

TABEL II. HASIL PENGUJIAn SENSOR PH METER

\begin{tabular}{|c|c|c|c|}
\hline Larutan & $\begin{array}{c}\text { Alat ukur } \\
\mathbf{p H} \text { manual } \\
\text { (pH) }\end{array}$ & $\begin{array}{c}\text { Sensor } \\
\mathbf{p H} \text { meter } \\
\mathbf{( \mathbf { p H } )}\end{array}$ & $\begin{array}{c}\text { Selisih } \\
\mathbf{( p H )}\end{array}$ \\
\hline Asam (borax) & 4,5 & 4,1 & 0,4 \\
\hline Normal & 7 & 6,6 & 0,4 \\
\hline Basa (sabun) & 9 & 8,6 & 0,4 \\
\hline
\end{tabular}

\section{B.2. Pengujian Sensor Ultrasonik}

Pengujian sensor ultrasonik ini, sensor ini ditempatkan pada bagian dalam akuaponik yang telah dibuat. Melakukan pengujian terhadap sensor agar dapat membaca ketinggian air. Pengujian dilakukan dengan melakukan pengukuran dari beberapa jarak sensor ultrasonik terhadap permukaan air. Hasil yang didapat memiliki toleransi error sebesar 7,8\% dari meter ukur manual sebagai nilai sebenarnya. Berdasarkan pengujian yang dilakukan, maka didapatkan hasil seperti pada Tabel III.

TABEL III. HASIL PENGUJIAN SENSOR UltrasoniK

\begin{tabular}{|c|c|c|}
\hline $\begin{array}{c}\text { Sensor } \\
\text { ultrasonic (cm) }\end{array}$ & $\begin{array}{c}\text { Meter ukur } \\
\text { manual (cm) }\end{array}$ & Selisih (cm) \\
\hline 45 & 46 & 1 \\
\hline 38 & 37,9 & 0,1 \\
\hline 31 & 32,5 & 1,5 \\
\hline 26 & 26,7 & 0,7 \\
\hline 18 & 19 & 1 \\
\hline 11 & 11,8 & 0,8 \\
\hline 2 & 3 & 1 \\
\hline
\end{tabular}

\section{B.3. Pengujian Fungsi Keseluruhan Sistem}

Pengujian fungsi sensor keseluruhan sistem ditempatkan pada bagian dalam akuaponik yang telah dibuat. Melakukan pengujian terhadap sensor yang dilakukan selama tiga hari, pengecekan kadar $\mathrm{pH}$ menggunakan alat ukur $\mathrm{pH}$ manual dilakukan lima kali dalam sehari dalam waktu yang berbeda-beda dan dicatat kadar $\mathrm{pH}$ dan ketinggian air. Berdasarkan pengujian yang dilakukan, maka didapatkan hasil seperti pada Tabel IV.

TABEL IV. Hasil Pengujian Fungsi SEnsor KesEluruhan SISTEM

\begin{tabular}{|c|c|c|c|c|}
\hline \multicolumn{2}{|c|}{ waktu } & \multirow{2}{*}{$\begin{array}{c}\text { Alat } \\
\text { ukur pH } \\
\text { manual } \\
(\mathrm{pH})\end{array}$} & \multirow{2}{*}{$\begin{array}{l}\text { Sensor } \\
\text { pH } \\
\text { meter } \\
(\mathrm{pH})\end{array}$} & \multirow{2}{*}{$\begin{array}{c}\text { Ketinggian } \\
\text { Air }(\mathrm{cm})\end{array}$} \\
\hline Hari & Jam & & & \\
\hline \multirow{5}{*}{$\begin{array}{c}\text { Hari } \\
\text { Pertama }\end{array}$} & $10: 48: 38$ & 6.9 & 6.79 & 43 \\
\hline & $15: 46: 41$ & 7.0 & 6.78 & 43 \\
\hline & $20: 42: 23$ & 7.0 & 6.77 & 43 \\
\hline & $01: 43: 00$ & 6.9 & 6.58 & 42 \\
\hline & $05: 23: 00$ & 7.0 & 6.77 & 42 \\
\hline \multirow{5}{*}{$\begin{array}{c}\text { Hari } \\
\text { Kedua }\end{array}$} & 08:54:00 & 7.1 & 6.73 & 42 \\
\hline & $13: 15: 28$ & 7.1 & 6.64 & 38 \\
\hline & $17: 50: 54$ & 7.1 & 6.47 & 37 \\
\hline & $23: 28: 18$ & 6.8 & 5.53 & 37 \\
\hline & $06: 13: 56$ & 7.0 & 5.73 & 31 \\
\hline \multirow{5}{*}{$\begin{array}{c}\text { Hari } \\
\text { Ketiga }\end{array}$} & $11: 48: 34$ & 6.8 & 5.37 & 44 \\
\hline & $16: 24: 17$ & 6.9 & 6.0 & 42 \\
\hline & $00: 55: 40$ & 7.0 & 6.1 & 43 \\
\hline & $05: 56: 28$ & 7.0 & 6.15 & 43 \\
\hline & $10: 52: 21$ & 7.0 & 5.87 & 41 \\
\hline
\end{tabular}

Berdasarkan hasil pengujian sistem akuaponik yang ditampilkan pada Tabel IV, terjadi perubahan $\mathrm{pH}$ dan ketinggian air pada jam 06:13 di hari kedua dengan nilai kadar $\mathrm{pH}$ sebesar $5.73 \mathrm{pH}$ dan nilai ketinggian air $31 \mathrm{~cm}$ yang menyebabkan perhitungan fuzzy menampilkan hasil kesimpulan untuk "Tambah Air Rendah" pada akuaponik. Perubahan pH dan ketinggian air pada jam 11:48 di hari ketiga dengan nilai kadar $\mathrm{pH}$ sebesar $5.37 \mathrm{pH}$ dan nilai ketinggian air $44 \mathrm{~cm}$ yang menyebabkan perhitungan fuzzy menampilkan hasil kesimpulan untuk "Ganti air" pada akuaponik. Sehingga peneliti melakukan pergantian air pada akuaponik. Setelah peneliti melakukan pergantian air, pada jam 16:24 di hari ketiga sistem menampilan keadaan nilai kadar $\mathrm{pH}$ menjadi $6.0 \mathrm{pH}$ dan nilai ketinggian air menjadi $42 \mathrm{~cm}$ menyebabkan perhitungan fuzzy menampilkan hasil kesimpulan untuk "Tidak Ada" sampai pada jam 10:52 di hari ketiga pada akuaponik. Hal tersebut menunjukkan bahwa sistem akuaponik berjalan sesuai dengan yang diharapkan.

Gambar 15 merupakan hasil perhitungan secara manual dengan perbandingan hasil dari masukan nilai $\mathrm{pH}$ dan ketinggian air sesuai dengan hasil penelitian yaitu kadar $\mathrm{pH}(5,73 \mathrm{pH})$ dan ketinggian air $(31 \mathrm{~cm})$.

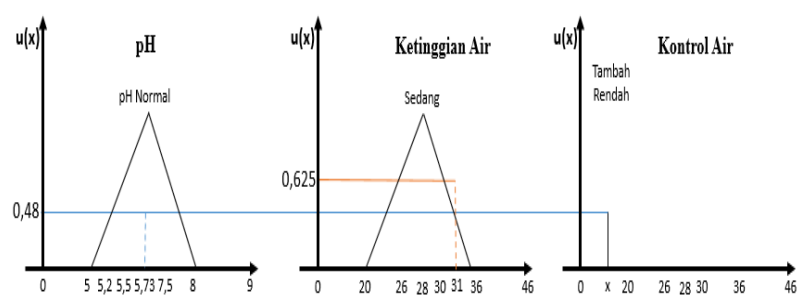

Gambar 15. Hasil Perhitungan Secara Manual 
Tabel hasil perhitungan secara manual dengan perbandingan hasil dari masukan nilai $\mathrm{pH}$ dan ketinggian air sesuai hasil penelitian menghasilkan kombinasi aturan fuzzy yaitu kadar pH normal $(0,48)$ dan ketinggian air sedang $(0,625)$ dengan hasil tambah rendah $(16,16 \mathrm{~cm})$, dapat dilihat pada Tabel V.

TABEL V. Hasil Perhitungan Secara Manual

\begin{tabular}{|c|l|c|c|}
\hline Perhitungan & Kadar $\mathrm{pH}$ & $\begin{array}{c}\text { Ketinggian } \\
\text { Air }\end{array}$ & Hasil \\
\hline Manual & $\begin{array}{l}\text { Normal } \\
(0,48)\end{array}$ & $\begin{array}{l}\text { Sedang } \\
(0,625)\end{array}$ & $\begin{array}{c}\text { Tambah } \\
\text { Rendah } \\
(16,16 \mathrm{~cm})\end{array}$ \\
\hline
\end{tabular}

Gambar 16 merupakan hasil perhitungan menggunakan sistem dengan perbandingan hasil dari masukan nilai $\mathrm{pH}$ dan ketinggian air sesuai dengan hasil penelitian yaitu kadar $\mathrm{pH}(5,73 \mathrm{pH})$ dan ketinggian air (31 $\mathrm{cm})$.

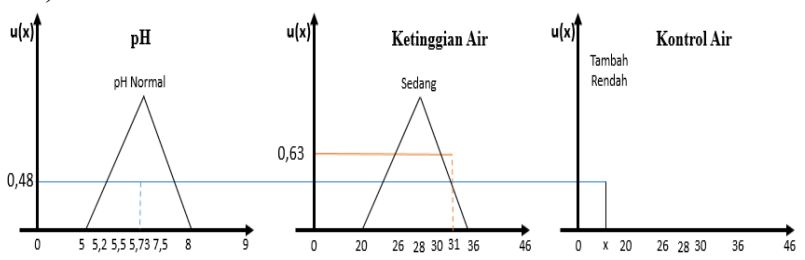

Gambar 16. Hasil Kurva Perhitungan Menggunakan Sistem

Tabel hasil perhitungan menggunakan sistem dengan perbandingan hasil dari masukan nilai $\mathrm{pH}$ dan ketinggian air sesuai hasil penelitian menghasilkan kombinasi aturan fuzzy yaitu kadar pH normal $(0,48)$ dan ketinggian air sedang $(0,63)$ dengan hasil tambah rendah $(16,11 \mathrm{~cm})$, dapat dilihat pada Tabel VI.

TABEL VI. HASIL PERHITUNGAN MENGGUNAKAN SISTEM

\begin{tabular}{|c|l|c|c|}
\hline Perhitungan & Kadar $\mathrm{pH}$ & $\begin{array}{c}\text { Ketinggian } \\
\text { Air }\end{array}$ & Hasil \\
\hline $\begin{array}{c}\text { Sistem } \\
\text { Akuaponik }\end{array}$ & $\begin{array}{l}\text { Normal } \\
(0,48)\end{array}$ & $\begin{array}{c}\text { Sedang } \\
(0,63)\end{array}$ & $\begin{array}{c}\text { Tambah } \\
\text { Rendah } \\
(16,11 \mathrm{~cm})\end{array}$ \\
\hline
\end{tabular}

Tabel hasil perhitungan keputusan fuzzy sesuai dengan hasil pengujian sistem berdasarkan data yang didapat pada selama penelitian dapat dilihat pada Tabel VII.

TABEL VII. HASIL PERHITUNGAN KePUTUSAN FuZZY

\begin{tabular}{|c|c|c|c|c|}
\hline \multicolumn{2}{|c|}{ Waktu } & \multirow{2}{*}{$\begin{array}{c}\text { Kadar } \\
\text { pH }\end{array}$} & \multirow{2}{*}{$\begin{array}{c}\text { Ketinggian } \\
\text { Air }\end{array}$} & \multirow{2}{*}{ Kesimpulan } \\
\hline Hari & Jam & & & \\
\hline Kedua & $06: 13: 56$ & $\begin{array}{c}\text { Normal } \\
(0.48)\end{array}$ & $\begin{array}{l}\text { Sedang } \\
(0.63)\end{array}$ & $\begin{array}{c}\text { Tambah Air } \\
\text { Sedikit } \\
(16,11)\end{array}$ \\
\hline Ketiga & $11: 48: 34$ & $\begin{array}{c}\text { Rendah } \\
(0.25)\end{array}$ & Tinggi (1) & $\begin{array}{c}\text { Ganti Air } \\
(30,08)\end{array}$ \\
\hline Ketiga & $16: 24: 17$ & $\begin{array}{c}\text { Normal } \\
(0.67)\end{array}$ & Tinggi (1) & $\begin{array}{l}\text { Tidak Ada } \\
(0)\end{array}$ \\
\hline
\end{tabular}

Berdasarkan hasil keputusan fuzzy yang ditampilkan pada Tabel VII, pada jam 6:13 di hari kedua terjadi pemberitahuan hasil kesimpulan yaitu "Tambah Air Rendah" dengan melakukan penambahan air sebanyak $16,16 \mathrm{~cm}$ pada kolam ikan di akuaponik. Kemudian pada jam 11:48 di hari ketiga terjadi pemberitahuan hasil kesimpulan yaitu "Ganti Air" dengan melakukan pengurasan pada air kolam, setelah dilakukan pengurasan air diisi kembali sebanyak 30,08 cm pada kolam ikan di akuaponik. Kemudian pada jam 16:24 di hari ketiga terjadi pemberitahuan hasil kesimpulan yaitu "Tidak Ada" maka akuaponik dalam kondisi aman.

Tabel hasil pengujian perhitungan pada sistem dengan perhitungan manual dapat dilihat pada Tabel VIII.

TABEL VIII. Hasil PengujIan Perhitungan

\begin{tabular}{|c|c|c|c|c|c|}
\hline \multirow{2}{*}{ No } & \multicolumn{2}{|c|}{ Input } & \multicolumn{2}{c|}{$\begin{array}{c}\text { Hasil Perhitungan } \\
(\mathrm{cm})\end{array}$} & \multirow{2}{*}{ Keterangan } \\
\cline { 2 - 5 } & $\begin{array}{c}\mathrm{pH} \\
(\mathrm{pH})\end{array}$ & $\begin{array}{c}\text { Ketinggian } \\
\text { Air }(\mathrm{cm})\end{array}$ & Manual & Sistem & \\
\hline 1 & 5,73 & 31 & $\begin{array}{c}\text { Tambah } \\
\text { Rendah } \\
(16,16)\end{array}$ & $\begin{array}{c}\text { Tambah } \\
\text { Rendah } \\
(16,11)\end{array}$ & $\begin{array}{c}\text { Sudah } \\
\text { Sesuai }\end{array}$ \\
\hline 2 & 5,37 & 44 & $\begin{array}{c}\text { Ganti } \\
\text { Air } \\
(30,08)\end{array}$ & $\begin{array}{c}\text { Ganti } \\
\text { Air } \\
(30,08)\end{array}$ & $\begin{array}{c}\text { Sudah } \\
\text { Sesuai }\end{array}$ \\
\hline 3 & 6 & 42 & $\begin{array}{c}\text { Tidak } \\
\text { Ada }(0)\end{array}$ & $\begin{array}{c}\text { Tidak } \\
\text { Ada }(0)\end{array}$ & $\begin{array}{c}\text { Sudah } \\
\text { Sesuai }\end{array}$ \\
\hline
\end{tabular}

Berdasarkan hasil pengujian perhitungan yang ditampilkan pada Tabel VIII menunjukkan hasil pengujian perhitungan pada sistem dengan perhitungan manual. Pada tabel tersebut perhitungan pada sistem memiliki hasil yang sama atau sudah sesuai dengan perhitungan manual, meskipun terdapat sedikit perbedaan pada nilai dibelakang koma (,) hal tersebut karena proses pembulatan pada perhitungan manual dan sistem.

\section{KESIMPULAN DAN SARAN}

\section{A. Kesimpulan}

Berdasarkan penelitian yang telah dilakukan, maka mendapatkan hasil kesimpulan sebagai berikut.

1. Sistem akuaponik yang dibuat dapat berjalan dengan baik, dan menunjukkan informasi berdasarkan hasil dari perhitungan fuzzy.

2. Sensor $\mathrm{pH}$ meter dapat mengukur kadar $\mathrm{pH}$ air pada akuaponik dengan toleransi error sebesar $6,3 \%$ dari alat ukur $\mathrm{pH}$ manual.

3. Sensor ultrasonik dapat mengukur ketinggian air pada akuaponik dengan toleransi error sebesar 7,8\% dari pengukuran menggunakan meter ukur manual.

4. Sistem akuaponik dapat menampilkan kesimpulan perhitungan hasil fuzzy sesuai dengan data kadar $\mathrm{pH}$ dan ketinggian air yang didapatkan dari sensor.

5. Hari pertama menunjukkan kondisi akuaponik aman dengan adanya keputusan kesimpulan "Tidak Ada". Kemudian terjadi perubahan keputusan pada hari kedua dan ketiga dengan adanya keputusan kesimpulan 
"Tambah Air Sedikit" dan "Ganti Air". Perubahan keputusan dengan kelipatan satu hari.

6. Perhitungan pada sistem memiliki hasil yang sama atau sudah sesuai dengan perhitungan manual, meskipun terdapat sedikit perbedaan pada nilai dibelakang koma (,) hal tersebut karena proses pembulatan pada perhitungan manual dan sistem.

\section{B. Saran}

Jika dilakukan penelitian lebih lanjut, maka diperlukan beberapa saran sebagai berikut.

1. Membuat sistem pergantian air secara otomatis saat hasil perhitungan fuzzy menunjukkan kesimpulan "Ganti Air" atau "Tambah Air".

2. Evaluasi hanya tiga hari, sehingga kedepan diharapkan untuk diuji pada jangka waktu lebih lama, untuk mengetahui kelipatan keputusan.

\section{DAFTAR PUSTAKA}

[1] K. K. A. K. M. 2010, Buku Putih Sanitasi, Mataram, 2010.

[2] B. C. J. Kesuma, Tibyani and M. H. H. Ichsan, "Implementasi Metode Fuzzy Pada Akuaponik Deep Water Culture Berdasarkan Derajat Keasaman Dan Ketinggian Air," Jurnal Pengembangan Teknologi Informasi dan Ilmu Komputer, vol. 2, no. 11, p. 5193, 2018.

[3] L. T. P. Ristiawan Agung Nugroho1, D. Chilmawati1 and A. H. C. Haditomo, "Aplikasi Teknologi Akuaponik Pada Budidaya Ikan Air Tawar Untuk Optimalisasi kapasitas Produksi," Jurnal Saintek Perikanan, vol. 8, no. 1, 2012.
[4] M. I. Mahali, "Smart Door Locks Based On Internet of Things Concept With Mobile Backend as a Service," Jurnal Electronics, Informatics, and Vocational Education (ELINVO), vol. 1, no. 3, 2016.

[5] D. I. Verananda, S. Hardhienata and A. Qur"eania, "Sistem Identifikasi Kualitas Air Kolam Ikan Koi Menggunakan Metode Fuzzy Tsukamoto," Program Studi Ilmu Komputer FMIPA Universitas Pakuan.

[6] A. Qalit, Fardian and A. Rahman, "Rancang Bangun Prototipe Pemantauan Kadar pH dan Kontrol Suhu Serta Pemberian Pakan Otomatis pada Budidaya Ikan Lele Sangkuriang Berbasis IoT," KITEKTRO: Jurnal Online Teknik Elektro, vol. 2, no. 3, 2017.

[7] G. Imaduddin and A. Saprizal, "Otomatisasi Monitoring Dan Pengaturan Keasaman Larutan Dan Suhu AIr Kolam Ikan Pada Pembenihan Ikan Lele," Jurnal Sistem Informasi, Teknologi Informatika dan Komputer, vol. 7, no. 2.

[8] M. Maslim, B. Y. Dwiandiyanta and N. V. Susilo, "Implementasi Metode Logika Fuzzy dalam Pembangunan Sistem Optimalisasi Lampu Lalu Lintas," Jurnal Buana Informatika, vol. 9, p. 1, 2018.

[9] M. D. Nurmansyah and Supriyono, "Autotuning Parameter Kendali PD Dengan Tsukamoto Fuzzy Menggunakan Bahasa C," ISSN, vol. 5022, p. 1907, 2011.

[10] P. I. A. Guna, I. M. A. Suyadnya and I. G. A. P. R. Agung, "Sistem Monitoring Penetasan Telur Penyu Menggunakan Mikrokontroler NodeMCU ESP8266 dan Protokol MQTT dengan Notifikasi Berbasis Telegram Messenger," $J$ COSINE, vol. 2, p. 2, 2018. 